\title{
Characterization of Organoferroelasticity in a TEMPO crystal
}

Subham Ranjan and Satoshi Takamizawa*

Department of Materials System Science, Graduate School of Nanobioscience

Yokohama City University

22-2 Seto, Kanazawa-ku, Yokohama, Kanagawa 236-0027 (Japan)

E-mail: staka@yokohama-cu.ac.jp

Table of contents:

Thermal analysis

Mechanical properties

Crystallographic studies

Supporting references
Page

S1

S1-S4

S4-S6

S7

\section{Other supporting material}

Movie S1. Ferroelastic behavior of a crystal of TEMPO by shearing with tweezers at room temperature under an optical microscope equipped with polarizing plates. 
(a)

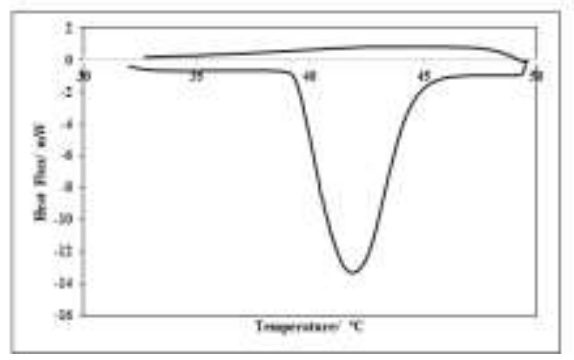

(b)

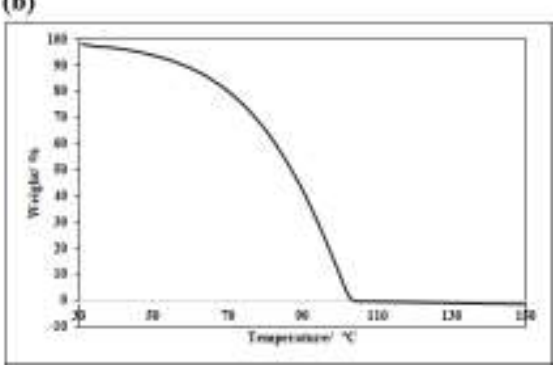

Figure S1. (a) DSC curve and (b) Thermogravimetric profile of TEMPO.

Table S1 . Comparison of forward and reverse stress among organoferroelastic materials.

$\begin{array}{lll}\text { Compounds } & \text { Forward stress }\left(\sigma_{\mathrm{f}} / \mathrm{MPa}\right) & \text { Reverse stress }\left(\sigma_{\mathrm{r}} / \mathrm{MPa}\right) \\ \text { CPE }(\text { r.t. })^{\mathrm{i}} & 0.21 & 0.14 \\ \text { CNA (r.t. })^{\mathrm{ii}} & 0.33 & 0.39 \\ 1.2\left(50{ }^{\circ} \mathrm{C}\right)^{\mathrm{iii}} & 0.37 & 0.22 \\ \text { DEB (r.t. })^{\mathrm{iv}} & 0.40 & 0.05-0.11 \\ \text { ADA (r.t. })^{\mathrm{v}} & 0.50 & 0.50 \\ \text { CDA (r.t. })^{\mathrm{vi}} & 0.70 & 0.70 \\ \text { TEMPO } & \mathbf{1 . 1 8} & \mathbf{0 . 8 6} \\ 1.2 \text { (r.t. })^{\mathrm{iii}} & 1.32 & 1.65 \\ \text { MNA (r.t. })^{\text {vii }} & 6.89 & \end{array}$

i. $\quad$ 4,4'-Dicarboxydiphenyl ether, ${ }^{1}$ ii. $\quad$ 5-Chloro-2-nitroaniline, ${ }^{2}$ iii. Cocrystal of oxalic acid and 4-chlorobenzamide, ${ }^{3}$ iv. 1,4-Diethoxybenzene, ${ }^{4}$ v. Adipic acid, ${ }^{5}$ vi. 1,4-Cyclohexanedicarboxylic acid, ${ }^{6}$ and vii. 2-Methyl-5-nitrobenzoic acid ${ }^{7}$. 
Three-point bending tests. Three-point bending test experiments were carried out by using a universal testing machine at room temperature. A single crystal was placed on two-point support, and then the force was applied on the crystal by a metal-blade jig (Fig. S2). The face $(0 \overline{1} 0 / 010)$ of the crystal was pushed downward (press) by the jig at a displacement rate of $2 \mu \mathrm{m} \mathrm{sec}^{-1}$. After bending, the force was released, and deformation behavior was examined under a polarized microscope. From the three-point bending test, displacement with respect to force applied is obtained. It is then converted to stress and strain by the following equation, where $\mathrm{L}$ is the support span $(\mathrm{mm})$, and $\mathrm{D}$ is the maximum deflection of the center $(\mathrm{mm})$.

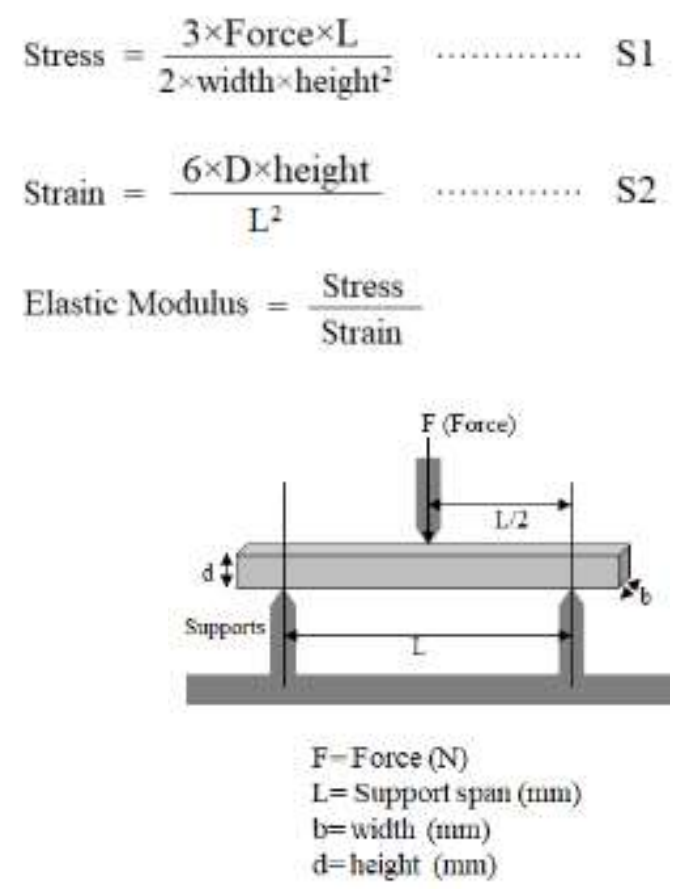

Figure S2. Experimental setup. A single crystal was kept on two-point supports, and then the load was applied to the crystal by a metal-blade jig. 

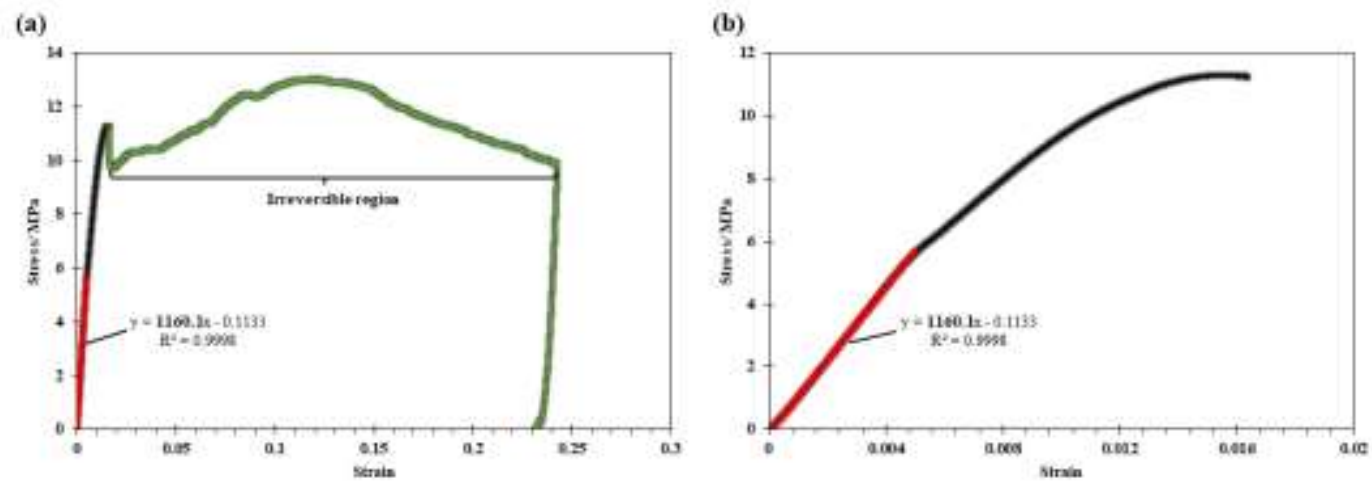

Figure S3. (a) Stress-strain curve of TEMPO by three-point bending test and (b) Linear curve fitting in the elastic region of the stress-strain curve (red color).

Table S2. Crystallographic data for TEMPO

\begin{tabular}{|l|l|l|}
\hline Domain & $\alpha_{\mathrm{M}}$ & $\alpha_{\mathrm{D}}$ \\
\hline $\mathrm{T} / \mathrm{K}$ & $243(2)$ & $243(2)$ \\
\hline Empirical formula & $\mathrm{C}_{9} \mathrm{H}_{18} \mathrm{NO}$ (Mother Domain) & $\mathrm{C}_{9} \mathrm{H}_{18} \mathrm{NO}$ (Daughter Domain) \\
\hline Crystal system & Monoclinic & Monoclinic \\
\hline Space group & $\mathrm{Cm}$ & $\mathrm{Cm}$ \\
\hline$a / \AA$ & $6.5552(6)$ & $6.5561(10)$ \\
\hline$b / \AA$ & $14.3368(13)$ & $14.339(2)$ \\
\hline$c / \AA$ & $5.8374(5)$ & $5.8411(9)$ \\
\hline$\alpha /{ }^{\circ}$ & 90.00 & 90.00 \\
\hline$\beta /{ }^{\circ}$ & $118.447(3)$ & $118.499(5)$ \\
\hline$\gamma /{ }^{\circ}$ & 90.00 & 90.00 \\
\hline $\mathrm{V} / \AA 3$ & $482.36(8)$ & $482.57(13)$ \\
\hline $\mathrm{Z}$ & 2 & 2 \\
\hline$\rho_{\text {calcd }}\left[\mathrm{g} \mathrm{cm}{ }^{-3}\right]$ & 1.076 & 1.075 \\
\hline$F[000]$ & 174 & \\
\hline & & \\
\hline
\end{tabular}




\begin{tabular}{|l|l|l|}
\hline$\mu\left[\mathrm{mm}^{-1}\right]$ & 0.069 & 0.069 \\
\hline index ranges & $-7 \leq \mathrm{h} \leq 7,-16 \leq \mathrm{k} \leq 16,-6 \leq 1 \leq 6$ & $-7 \leq \mathrm{h} \leq 7,-16 \leq \mathrm{k} \leq 16,-6 \leq 1 \leq 6$ \\
\hline Reflections collected & 2930 & 3331 \\
\hline Goodness of fit & 1.158 & 1.127 \\
\hline$R_{1}(I>2 \sigma($ all data $))$ & 0.0389 & 0.0468 \\
\hline w $R_{2}(I>2 \sigma$ (all data $\left.)\right)$ & 0.0955 & 0.1166 \\
\hline $\mathrm{CCDC}$ No. & 2113191 & 2113192 \\
\hline
\end{tabular}
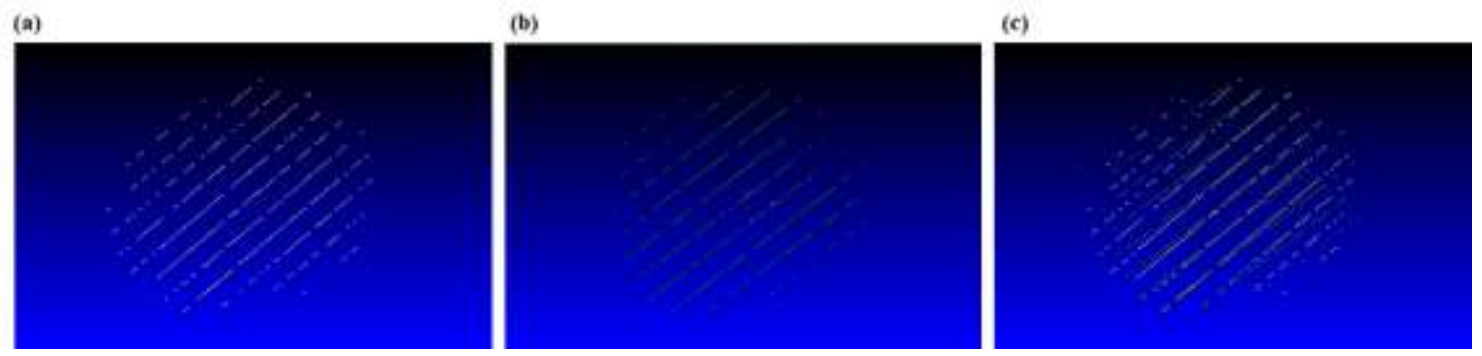

Figure S4. Portion of the reciprocal lattices. (a) Mother domain (b) Daughter domain, and (c) combined mother and daughter domain.
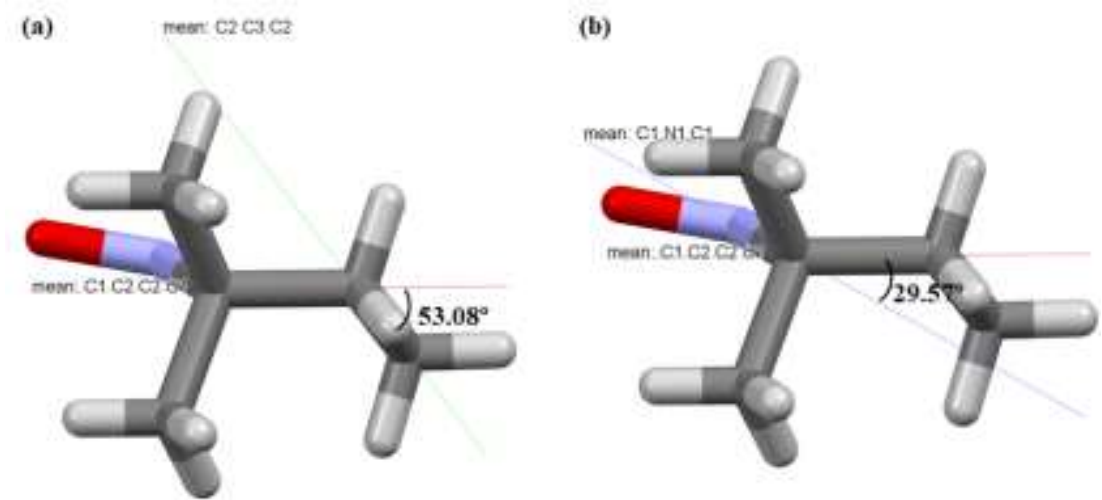

Figure S5. Dihedral angles between the planes help to form chair conformation. (a) Dihedral angles between the plane $\mathrm{C}(1)-\mathrm{C}(2)-\mathrm{C}(2)-\mathrm{C}(1)$ and plane $\mathrm{C}(2)-\mathrm{C}(3)-\mathrm{C}(2)$ and (b) Dihedral angles between the plane $\mathrm{C}(1)-\mathrm{C}(2)-\mathrm{C}(2)-\mathrm{C}(1)$ and the plane $\mathrm{C}(1)-\mathrm{N}(1)-\mathrm{C}(1)$. 
(a)

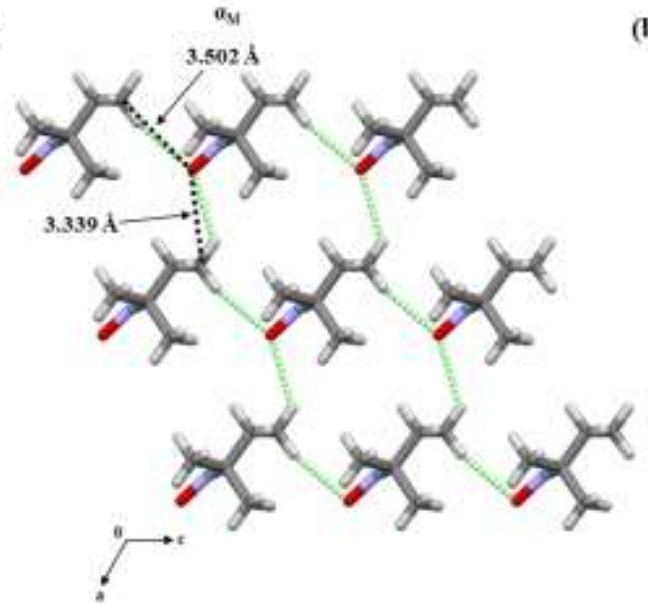

(b)

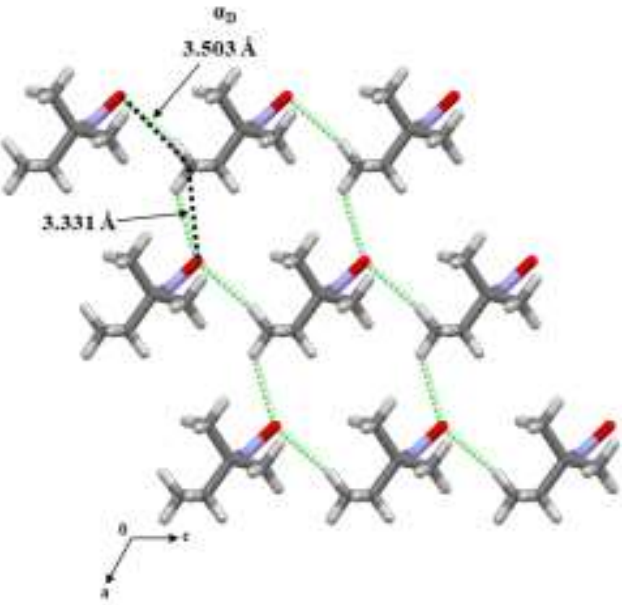

Figure S6. Crystal packing representation of (a) $\alpha_{M}$ domain and (b) $\alpha_{D}$ domain, which interact via $\mathrm{C}-\mathrm{H} \cdots \mathrm{O}$ interactions.

(a)

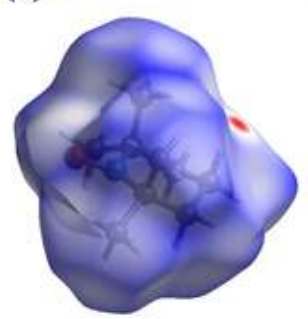

(b)

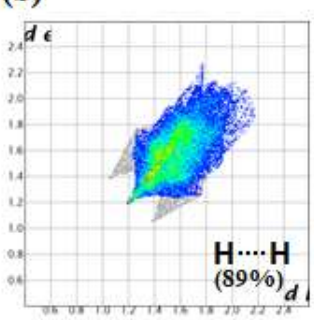

(c)

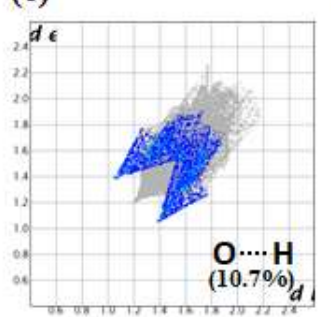

(d)

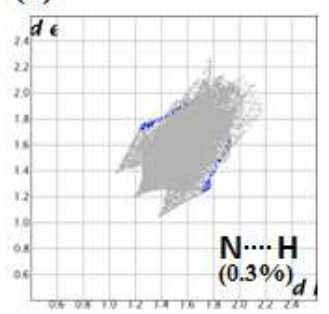

Figure S7. (a) Relative contributions of intermolecular interactions to the Hirshfeld surface area of TEMPO and (b), (c) and (d) are the Hirshfeld surface finger print plots from higher \% interaction to lower \% interaction. 


\section{References}

1. Engel, E. R.; Takasaki, Y.; Mir, S. H.; Takamizawa, S. Twinning Ferroelasticity Facilitated by the Partial Flipping of Phenyl Rings in Single Crystals of 4,4'Dicarboxydiphenyl Ether. R. Soc. open sci. 2018, 5 (1), 171146.

2. Mir, S. H.; Takasaki, Y.; Engel, E. R.; Takamizawa, S. Ferroelasticity in an Organic Crystal: A Macroscopic and Molecular Level Study. Angew. Chem. Int. Ed. 2017, 56 (50), 15882-15885.

3. Sasaki, T.; Sakamoto, S.; Takamizawa, S. Organoferroelastic Crystal Prepared by Supramolecular Synthesis. Cryst. Growth Des. 2020, 20 (3), 1935- 1939.

4. Engel, E. R.; Takamizawa, S. Versatile Ferroelastic Deformability in an Organic Single Crystal by Twinning about a Molecular Zone Axis. Angew. Chem. Int. Ed. 2018, 57 (37), 11888-11892.

5. Mir, S. H.; Takasaki, Y.; Takamizawa, S. An Organoferroelasticity Driven by Molecular Conformational Change. Phys. Chem. Chem. Phys. 2018, 20, 4631-4635.

6. Mir, S. H.; Takasaki, Y.; Engel, E. R.; Takamizawa, S. Controllability of Coercive Stress in an Organoferroelasticity by Incorporation of Bulky Flipping Moiety in Molecular Crystal. CrystEngComm 2018, 20, 3807-3811.

7. Mir, S. H.; Takasaki, Y.; Engel, E. R. Takamizawa, S. Enhancement of Dissipated Energy by Large Bending of an Organic Single Crystal undergoing Twinning Deformation. RSC Adv. 2018, 8, 21933-21936. 